\title{
Brain metastasis as initial presentation of papillary adenocarcinoma of the lung: case report*
}

\author{
Metástase cerebral como apresentação inicial de adenocarcinoma papilífero de pulmão: relato de caso \\ Irving Gabriel Araújo Bispo ${ }^{1}$, Diego Teixeira Nascimento ${ }^{2}$, Karina Oliveira Ferreira ${ }^{3}$, Ricardo Fakhouri ${ }^{4}$, \\ Atilano Salvador Godinho5 ${ }^{5}$ Thiago de Oliveira Ferrão ${ }^{6}$
}

\begin{abstract}
The authors describe the case of a 33-year-old patient with history of seizures alone without any previous symptom, being diagnosed with brain metastases from primary papillary adenocarcinoma of the lung. Emphasis is given to the diagnostic investigation for brain metastasis and prognostic evaluation of papillary adenocarcinoma of the lung, and a brief literature review on such diseases is performed.
\end{abstract}

Keywords: Neoplastic metastasis; Papillary adenocarcinoma; Immunohistochemistry.

Resumo Os autores descrevem um caso de paciente de 33 anos de idade com história de crises convulsivas isoladas sem qualquer antecedente, sendo diagnosticadas metástases cerebrais tendo como sítio primário um adenocarcinoma papilífero de pulmão. É enfatizada a investigação diagnóstica para metástase cerebral e avaliação prognóstica do adenocarcinoma papilífero de pulmão, além de realizar breve revisão sobre essas doenças.

Unitermos: Metástase neoplásica; Adenocarcinoma papilar; Imuno-histoquímica.

Bispo IGA, Nascimento DT, Ferreira KO, Fakhouri R, Godinho AS, Ferrão TO. Brain metastasis as initial presentation of papillary adenocarcinoma of the lung: case report. Radiol Bras. 2013 Set/Out;46(5):313-316.

\section{INTRODUCTION}

Brain metastases represent the most frequent intracranial tumors in adults ${ }^{(1)}$. The reported incidence of brain metastasis has increased both because of developments in the diagnosis of small lesions detected at magnetic resonance imaging (MRI) and a more appropriate approach to the systemic extracerebral disease ${ }^{(2)}$. Computed tomog-

* Study developed at Hospital Universitário - Universidade Federal de Sergipe (HU-UFS), Aracaju, SE, Brazil.

1. MD, Resident of Medical Practice, Hospital Universitário - Universidade Federal de Sergipe (HU-UFS), Aracaju, SE, Brazil.

2. MD, Resident of Radiology and Imaging Diagnosis, Hos pital Universitário - Universidade Federal de Sergipe (HU-UFS), Aracaju, SE, Brazil.

3. MD, Clinical Oncologist, Hospital Universitário - Universidade Federal de Sergipe (HU-UFS), Aracaju, SE, Brazil.

4. Associate Professor of General Pathology and Patholog ical Anatomy, Universidade Federal de Sergipe (UFS), Aracaju, SE, Brazil.

5. MD, Radiologist, Residency Coordinator, Department of Radiology and Imaging Diagnosis, Hospital Universitário - Universidade Federal de Sergipe (HU-UFS), Aracaju, SE, Brazil.

6. Titular Member of Colégio Brasileiro de Radiologia e Diagnóstico por Imagem (CBR), Fellow PhD Degree and Residency Preceptor, Department of Radiology and Imaging Diagnosis, Hospital Universitário - Universidade Federal de Sergipe (HUUFS), Aracaju, SE, Brazil.

Mailing Address: Dr. Irving Gabriel Araújo Bispo. Avenida Augusto Franco, 3553, Condomínio Recanto dos Pássaros, Bloco I, ap. 504, Bairro Ponto Novo. Aracaju, SE, Brazil, 49047-040. E-mail: invingbispo@yahoo.com.br.

Received February 10, 2012. Accepted after revision April 1st, 2013 raphy $(\mathrm{CT})$ is the initial imaging method in the approach to brain diseases, but MRI is the best method to diagnose brain metastasis. The utilization of contrast agents increases the MRI sensitivity to identify patients with suspicion of brain metastasis, differentiating it from other lesions originating from the central nervous system $(\mathrm{CNS})^{(\mathbf{3}, 4)}$. Imaging findings that may be useful in the differential diagnosis of brain metastasis with other diseases include presence of multiple lesions; lesion location at the white-grey matter junction; circumscribed margins; great accumulation of vasogenic edema as compared with the lesion size ${ }^{(2)}$. Currently, with the use of advanced techniques, MRI can provide more than just lesions location and anatomic details. Among such techniques, spectroscopy, diffusion and perfusion are highlighted for providing information on the physiology and chemical composition of CNS tumors ${ }^{(\mathbf{3 , 4})}$. Even so in some cases the imaging features do not allow the distinction between brain metastasis and primary malignant tumors. In this setting, biopsy is required to define the primary lesion site. In patients submitted to brain biopsy without identification of a primary tumor, the pulmonary site should be the first focus to be evaluated. Poorly differentiated carcinomas arising from the lungs are hardly classified as some specific characteristics may be absent. Thus immunohistochemistry becomes imprescindible to define the type of lung cancer ${ }^{(\mathbf{5})}$.

In the present report, the authors describe the case of a previously healthy, 33year-old female patient presenting with seizures who was diagnosed with brain metastasis secondary to papillary adenocarcinoma of the lung.

\section{CASE REPORT}

A female, 33-year-old patient was admitted complaining of tonic-clonic seizure without any other previous seizure and was referred to the emergency hospital where she remained for 20 days, being submitted to MRI. Such study demonstrated the presence of several expansile cortical and subcortical masses in both brain hemispheres (Figure 1).

The patient was referred to the University Hospital for diagnosis elucidation. At admission, the patient did not show any significant alteration. Serologic tests for parasitic infection were negative and total abdominal and chest CT did not reveal any 

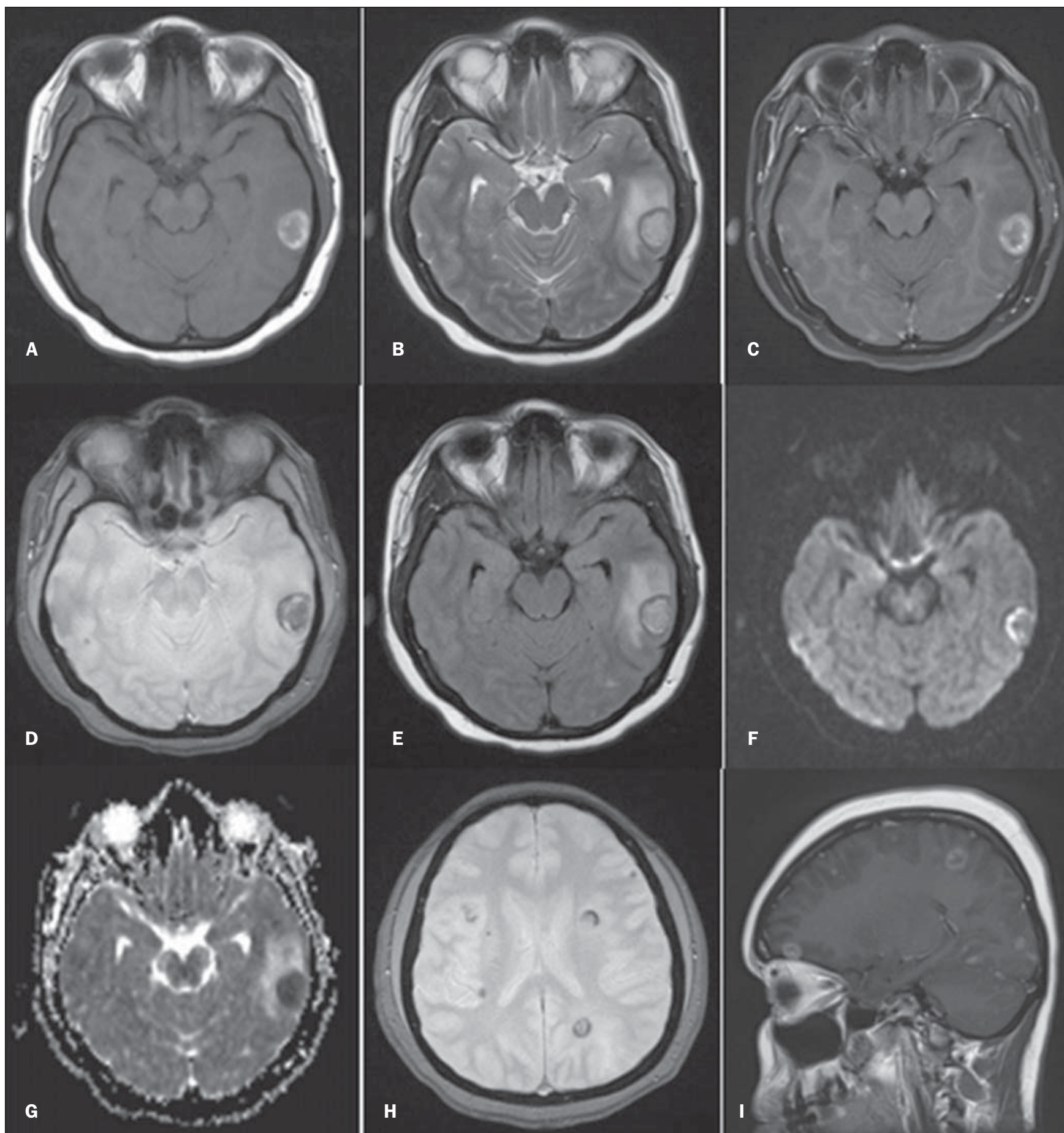

Figure 1. Cranial MRI. A: Axial, T1-weighted image - cortical-subcortical, expansile, nodular lesion in the left temporal lobe with a central isointense component and hypersignal halo. B: Axial, T2-weighted image - mild central hypersignal and peripheral hyposignal. C: Axial, contrast-enhanced T1-weighted image with fatsat - subtle peripheral gadolinium enhancement. D: Axial, T2-weighted image - marked and slightly heterogeneous hyposignal. E: Axial, FLAIR image - mild hypersignal in the central component and hyposignal halo, with perilesional edema. F: Axial, diffusion-weighted image. G: Axial, ADC mapping. H: Axial, T2weighted gradient image - multiple lesions with peripheral hyposignal. I: Sagittal, contrast-enhanced T1-weighted image - multiple lesions with ring-shaped uptake.

alteration. In the face of nonspecific findings, and considering the non-availability of perfusion and/or spectroscopy studies, brain biopsy was performed. The histopathological findings were suggestive of metastasis from papillary carcinoma. The thyroid was the probable site. At immunohistochemistry, the expression of TTF-1 and napsin-A markers (Figure 2), besides the negativity for thyroglobulin, identified the pulmonary tissue as the primary site brain metastasis from papillary adenocarcinoma of the lung.

The patient was referred for radiotherapy. After the third radiotherapy ses- 
Figure 2. Image showing immunohistochemistry test results with positive markers for TTF-1 (A) and napsin-A (B).

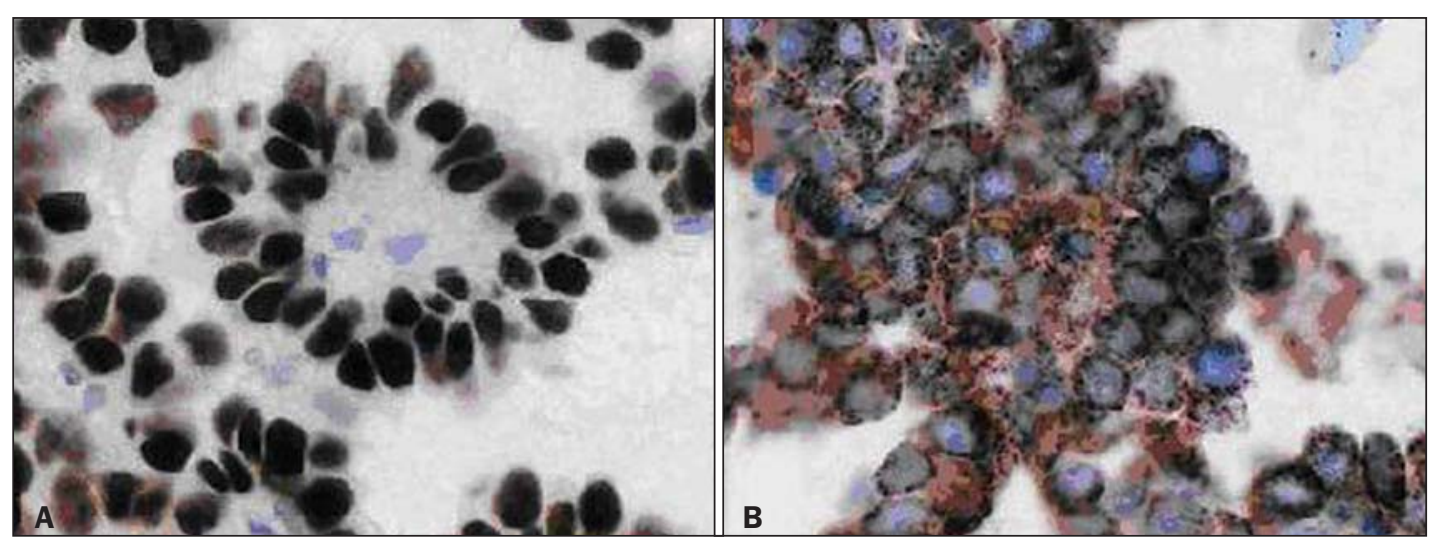

sion, she presented erythematous papular lesions on her face, besides papular lesions on her chest. The hypothesis of StevenJohnson syndrome was raised and the patient was transferred to the intensive care unit. After 45 days, the patient was discharged with scheduled continuation of radiotherapy sessions.

\section{DISCUSSION}

Brain metastases represent the most common intracranial tumors in adults. The most frequent primary carcinoma sites include lung, breast, kidney and colorectal. The clinical signs of brain metastasis are variable. Seizures in previously healthy patients are observed in $20 \%$ of cases $^{(\mathbf{1 , 6 )}}$. In the present case, the patient did not present any previous history of seizures. Besides general clinical tests, imaging investigation was indicated to rule out any disease. CT is the initial imaging method to be utilized in the suspicion of intracerebral neoplasm (either primary or secondary), mostly because of the easy access and swiftness of the examination. However, because of the lower anatomical resolution and/or the presence of small lesions with no hemorrhagic components, CT results may be dubious or even negative, so MRI utilizing contrast agents and advanced techniques as necessary is the most appropriate imaging method for the diagnosis of brain metastases ${ }^{(7)}$. CT presents good sensitivity in cases of brain lesions in association with hemorrhage, even if contrast agents are not utilized. In the present case, MRI demonstrated the presence of multiple, cortical and subcortical nodular lesions, bilaterally, with varied sizes and spontaneously hyperintense on T1- weighted sequences, possibly as a result from bleeding. Additionally, some lesions presented a halo corresponding to circumjacent vasogenic edema (Figure 1). In cases of brain metastases, the images are roundshaped, with iso- or hyposignal on T1weighted sequences, and iso-or hypersignal on T2-weighted sequences, besides a marked perilesional edema. Cystic degeneration and necrosis can also be detected by MRI, manifesting as areas of signal intensity similar to that of the cerebrospinal fluid $^{(4)}$. The spontaneous hypersignal pattern on T1-weighted images may also occur in cases of secondary hemorrhagic implantation or melanomas. Primary tumors most frequently associated with hemorrhagic metastases include renal tumors, thyroid tumors, melanomas and choriocarcinomas. In many cases, metastases from adenocarcinoma present hyposignal on T2weighted sequences. In cases where solid lesions are not associated with hemorrhagic components, the enhancement is usually peripheral on both methods ${ }^{(4)}$. It is important to observe that in most cases MRI cannot define the primary origin of the me$\operatorname{tastasis}^{(\mathbf{8})}$. The patterns observed in cases of secondary brain neoplasms by means of advanced MRI techniques include increased amounts of lactate, choline and lipid and decreased N-acetylaspartate at spectroscopy. Depending on the histological grade of the metastatic lesion, the diffusion may be either restricted or facilitated. In cases of hemorrhage, a false hypersignal is observed on diffusion-weighted images, as a result of an artifact produced by the presence of blood. Such data are useful in the differential diagnosis with inflammatory and infectious processes, since most of times such processes restrict the diffusion and the perfusion is said to be "cold" (low capillary density). Several authors have demonstrated lower values for relative cerebral blood volume (rCBV) in metastases as compared with multiform glioblastomas (primary tumors), except for hypervascular metastases such as renal carcinomas and melanomas which present higher rCBV values as compared with high grade glial tumors and other secondary lesions. Metastases present well-defined limits, with displaced and non infiltrated brain parenchyma; and this seems to be the main explanation for the rCBV efficacy in the differentiation between metastases and brain tumors $^{(4)}$. A study developed by Itagiba et al. on the role of diffusion tensor MRI in the assessment of white matter involvement in 44 patients with brain tumors, have demonstrated four patterns of involvement, namely, edematous, displaced, infiltrated and disrupted. In such series, the edematous and displaced patterns were found in patients with metastasis, but the second one is nonspecific for such a condition ${ }^{(9)}$. As regards primary neoplasms, the assessment of the peritumoral region is quite useful in the differentiation with metastases ${ }^{(10)}$.

Another point to be highlighted is role played by immunohistochemistry in the definition of the primary lesion site ${ }^{(5)}$. The thyroid transcription factor-1 (TTF-1) is the main immunohistochemical marker for pulmonary site. Napsin-A is abundant in the cytoplasm of pulmonary cells of lung $\operatorname{adenocarcinomas}^{(\mathbf{1 1})}$. Stoll et al. have demonstrated that TTF-1 and napsin-A can be markers for adenocarcinomas of probable pulmonary origin. Such authors have also demonstrated that napsin-A was more sen- 
sitive, as compared with TTF-1, to differentiate the papillary subtype of adenocarcinoma (96\% versus $78 \%$, respectively) ${ }^{(\mathbf{1 1})}$ Histopathological analysis demonstrated metastatic papillary carcinoma. Imaging studies did not detect any type of suspicious lesion, so immunohistochemistry, due to its broad spectrum, was fundamental to determine the disease site. Several factors play a significant role in the determination of brain metastases prognosis according to a combined classification system called recursive partitioning analysis (RPA) ${ }^{(6)}$.

As regards lung adenocarcinoma, Russell et al. have correlated survival with subtypes. In 26 cases of predominantly papillary adenocarcinoma, the five-year survival reached $71 \%$. As a comparison is made with other invasive adenocarcinoma subtypes, for example, it is observed that in 14 cases of the predominantly micropapillary subtype, the five-year survival reached $38 \%{ }^{(\mathbf{1 2})}$. Recent studies have correlated radiological findings with pathology results. In large centers, with the recent developments in imaging methods, it is starting to be possible to suspect the histological pattern of lung adenocarcinomas with basis on the tomographic pattern of the lesion ${ }^{(\mathbf{1 3})}$. So there is an opportunity for radiologists, pulmonologists and surgeons to get an early notion on the patients' prognosis, gaining time in the definition of the approach to be adopted ${ }^{(\mathbf{1 4})}$.
Finally, the present report describes a case of metastatic, hemorrhagic nodular lesions as initial manifestation of papillary adenocarcinoma of the lung, and emphasizes the relevance of MRI in the assessment of patients with seizures of probable secondary etiology, as well as the determining role of immunohistochemistry in the case definition.

\section{REFERENCES}

1. Sperduto PW, Chao ST, Sneed PK, et al. Diagnosis-specific prognostic factors, indexes, and treatment outcomes for patients with newly diagnosed brain metastases: a multi-institutional analysis of 4,259 patients. Int J Radiat Oncol Biol Phys. 2010;77:655-61.

2. Mehta MP. Current management of patients with metastatic brain tumors. Medscape Education Oncology. [acessado em 7 de junho de 2011]. Disponível em: http://www.medscape.org/ viewarticle/742360

3. Lacerda S, Law M. Magnetic resonance perfusion and permeability imaging in brain tumors. Neuroimaging Clin N Am. 2009;19:527-57.

4. Otaduy MCG, Toyama C, Nagae LM, et al. Técnicas de obtenção das imagens em neurorradiologia. In: Leite CC, editor. Neurorradiologia diagnósticos por imagens das alterações encefálicas. $1^{\text {a }}$ ed. Rio de Janeiro: Guanabara-Koogan; 2008. p. 1-47.

5. Capelozzi VL. Papel da imuno-histoquímica no diagnóstico do câncer de pulmão. J Bras Pneumol. 2009;35:375-82.

6. Caroli M, Di Cristofori A, Lucarella F, et al. Surgical brain metastases: management and outcome related to prognostic indexes: a critical review of a ten-year series. ISRN Surg. 2011;2011:207103.

7. Travis WD, Brambilla E, Noguchi M, et al. Inter- national association for the study of lung cancer/ american thoracic society/european respiratory society international multidisciplinary classification of lung adenocarcinoma. J Thorac Oncol. 2011;6:244-85.

8. Kieffer SA, Brace JR. Neoplasias intracranianas. In: Haaga JR, Dogra VS, Forsting M, et al, editores. TC e RM - uma abordagem do corpo humano completo. $5^{\text {a }}$ ed. Rio de Janeiro: Elsevier; 2010. p. 49-146.

9. Itagiba VGA, Borges R, Cruz Jr LCH, et al. Uso do tensor de difusão na avaliação dos padrões de acometimento da substância branca em pacientes com tumores cerebrais: é uma ferramenta útil para o diagnóstico diferencial? Radiol Bras. 2010; 43:362-8.

10. Al-Okaili RN, Krejza J, Wang S, et al. Advanced MR imaging techniques in the diagnosis of intraaxial brain tumors in adults. Radiographics. 2006;26:S173-89.

11. Stoll LM, Johnson MW, Gabrielson E, et al. The utility of napsin-A in the identification of primary and metastatic lung adenocarcinoma among cytologically poorly differentiated carcinomas. Cancer Cytopathol. 2010;118:441-9.

12. Russell PA, Wainer Z, Wright GM, et al. Does lung adenocarcinoma subtype predict patient survival?: A clinicopathologic study based on the new International Association for the Study of Lung Cancer/American Thoracic Society/European Respiratory Society international multidisciplinary lung adenocarcinoma classification. J Thorac Oncol. 2011;6:1496-504.

13. Maia Junior ACM, Lucas Junior A, Rocha AJ Neoplasias parenquimatosas infratentoriais. In: Silva CIS, D'Ippolito G, Rocha AJ, editores. Encéfalo. $1^{\mathrm{a}}$ ed. Rio de Janeiro: Elsevier; 2012. p. 323-53.

14. Dieu-Nosjean MC, Antoine M, Danel C, et al. Long-term survival for patients with non-smallcell lung cancer with intratumoral lymphoid structures. J Clin Oncol. 2008;26:4410-7. 